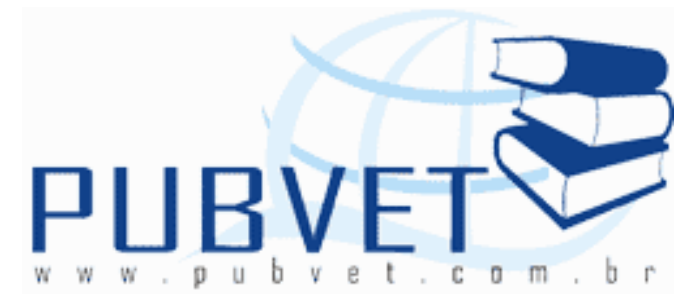

PUBVET, Publicações em Medicina Veterinária e Zootecnia.

\title{
Composição bromatológica de ração comercial para cães acondicionada de diferentes maneiras e por diferentes períodos
}

Kleber da Cunha Peixoto $\mathrm{Jr}^{1}$; Daniela Silva Rodrigues ${ }^{2}$; Valter Fontolan ${ }^{3}$

${ }^{1}$ Professor Titular da Universidade de Santo Amaro, Universidade Metodista de São Paulo e da Universidade Paulista

${ }^{2}$ Aluna de graduação da Universidade de Santo Amaro

${ }^{3}$ Técnico da Universidade de Santo Amaro

\section{Resumo}

Para avaliar o efeito do tipo e o tempo de armazenamento sobre a composição bromatológica de uma ração comercial para cães e avaliar a veracidade dos níveis de garantia presente no rótulo, foram utilizados seis sacos de ração comercial para cães de $15 \mathrm{~kg}$, divididos em 3 partes iguais: aberta, a granel e fechada, armazenadas durante 7 semanas e analisadas semanalmente para Umidade, Extrato Etéreo (EE), Matéria Mineral (MM), Fibra Bruta (FB), Proteína Bruta (PB), Matéria Seca (MS), Extrato Não-Nitrogenado (ENN), Cálcio (Ca) e Fósforo $(P)$. Os dados foram submetidos à análise de variância (PROC GLM) e análise de regressão (PROC REG). Pode-se observar que a quantidade de EE da amostra colhida após a abertura da embalagem foi inferior ao descrito nos níveis de garantia informados pelo fabricante. A umidade aumentou quando a ração foi armazenada aberta $(10,2 \% \times 7,5 \%$ e 7,8\%). Quando se avaliou o efeito do tempo de armazenamento sobre a composição bromatológica da 
ração, foram observadas alterações significativas apenas nos valores de umidade, PB e EE. Houve regressão linear positiva para umidade (Umidade = $7.4344+0,2895$ semana) e negativa para PB ( $P B=24,69-0,711$ semana) e $\mathrm{EE}$ ( $\mathrm{EE}=6,38-0,1465$ semana). Com isso pode-se concluir que $\mathrm{O}$ armazenamento de rações abertas aumenta a umidade do produto e que a quantidade de $\mathrm{PB}$ e EE diminuem linearmente com o aumento do tempo de armazenamento.

Palavras-chave: Composição, bromatológica e qualidade.

\section{Bromatologic composition of commercial diets for dogs stored in different ways and for different periods}

\section{Abstract}

To evaluate the effect of type and storage time on the bromatologic composition of a commercial food for dogs and to evaluate the veracity of this levels of guarantee on the label, we used six bag of commercial food for dogs of $15 \mathrm{~kg}$, divided into 3 equal parts : open, in bulk and closed, stored for 7 weeks and examined weekly for Humidity, Ether Extract (EE), Mineral Matter $(\mathrm{MM})$, Crude Fiber (CF), Crude Protein (CP), Dry Matter (DM), Statement No Nitrogen (SNN), Calcium (Ca) and Phosphorus (P). The data were subjected to analysis of variance (PROC GLM) and regression analysis (PROC REG). It can be observed that the quantity of EE in the sample after opening the package was less than the levels described by the manufacturer guarantee informed. The humidity increased when the feed was stored open $(10.2 \%$ vs. $7.5 \%$ and $7.8 \%)$. When evaluated the effect of storage time on the bromatologic composition of the diet, significant changes were observed only in the values of Humidity, CP and EE. There was a positive linear regression for humidity (Humidity $=7.4344+0.2895$ weeks $)$ and negative for $\mathrm{CP}(\mathrm{CP}=24.69$ to 0.711 week) and $\mathrm{EE}(\mathrm{EE}=6.38$ to 0.1465 week). With this we can conclude that the open storage of feed increases the humidity of the product and the quantity of $\mathrm{CP}$ and $\mathrm{EE}$ decrease linearly with increasing storage time.

Keywords: Composition, bromatologic and quality. 


\section{INTRODUÇÃO}

O Brasil está entre os maiores produtores mundiais de alimentos para cães e gatos, com mais de 500 marcas e 85 fabricantes. A competitividade desse mercado fez surgir uma grande variedade de produtos, com qualidades distintas [1].

A produção de alimentos completos para cães e gatos cresceu $7 \%$ em 2010, registrando pouco mais de dois milhões de toneladas. Apesar da grande capacidade local instalada para produção, apenas $45 \%$ da população de cães e gatos do Brasil alimenta-se do produto industrializado. O Sindicato Nacional da Indústria de Alimentação Animal (SINDIRAÇÕES) estima crescimento de $2 \%$ e produção de 2,12 milhões de toneladas de alimentos para cães e gatos em 2011 [2].

Segundo levantamento da AC Nielsen do Brasil (1997) [3], com dados de abril a maio, os supermercados são responsáveis por $40 \%$ das vendas de ração para cães e $39 \%$ dos alimentos de gatos. Pequenos estabelecimentos, como as lojas self-service (a granel), ficam com 19\%, nos dois tipos de ração.

Um dos fatores de risco para a saúde dos animais se refere à contaminação dos alimentos por fungos e outros microrganismos. Esta contaminação pode ocorrer desde a produção e armazenamento da matériaprima, principalmente os grãos, que são amplamente utilizados na fabricação de rações para várias espécies animais, até a industrialização e embalagem desse produto. Outros fatores de risco estão inerentes aos estabelecimentos comerciais, no que se refere ao armazenamento e a oferta do produto para os consumidores [4].

\section{OBJETIVO}

Os objetivos deste trabalho foram avaliar o efeito do tipo e o tempo de armazenamento sobre a composição bromatológica de uma ração comercial para cães e avaliar a veracidade dos níveis de garantia presente no rótulo. 


\section{MATERIAIS E MÉTODOS}

Este experimento foi realizado no setor de produção animal e no laboratório de bromatologia da Universidade de Santo Amaro, Campus I, São Paulo, SP.

Foram utilizados seis sacos de ração comercial para cães de $15 \mathrm{~kg}$ com os níveis de garantia descritos na tabela 1.

Tabela 1: Níveis de garantia da ração comercial utilizada neste experimento

\begin{tabular}{|c|c|c|c|c|c|c|}
\hline $\begin{array}{l}\text { UMIDADE } \\
\text { (*Máx) }\end{array}$ & $\begin{array}{c}\text { Proteína } \\
\text { Bruta } \\
\text { (**Min) }\end{array}$ & $\begin{array}{c}\text { Extrato } \\
\text { Etéreo } \\
\text { (Min) }\end{array}$ & $\begin{array}{l}\text { Fibra } \\
\text { Bruta } \\
\text { (Máx) }\end{array}$ & $\begin{array}{c}\text { Matéria } \\
\text { Mineral } \\
\text { (Max) }\end{array}$ & $\begin{array}{l}\text { Cálcio } \\
\text { (Max) }\end{array}$ & $F($ Min) \\
\hline $12,0 \%$ & $21,0 \%$ & $10,0 \%$ & $4,0 \%$ & $9,0 \%$ & $2,2 \%$ & $1,0 \%$ \\
\hline
\end{tabular}

*Máximo. **Mínimo.

As embalagens foram abertas no dia 04/05/2011, coletado uma amostra homogênea de aproximadamente $500 \mathrm{~g}$ de cada para análise imediata da composição bromatológica (inicial) e o restante foi dividido em 3 partes iguais:

a) Aberta (figura1): colocada em um recipiente aberto (balde tipo lixo capacidade $10 \mathrm{~kg}$ ),

b) A granel (figura 2): dividida em 7 subamostradas de aproximadamente $500 \mathrm{~g}$, acondicionadas em sacos plásticos e embaladas manualmente sem retirada de vácuo com seladora Everest modelo $\mathrm{X} e$

c) Fechada: permaneceu dentro do saco original fechada com cordas de nylon de $0,5 \mathrm{~mm}$.

Após aberto, as amostras permaneceram acondicionadas em uma sala fechada, com pouca iluminação e ampla ventilação. Durante 7 semanas, amostras semanais de cada uma das partes foram recolhidas e encaminhadas para análise. 
As amostras das rações foram trituradas, e em seguida acondicionadas em frascos plásticos fechados para posteriores análises.

As análises foram realizadas de acordo com os métodos da Association of Official Analytical Chemists [5].

Foram realizadas as seguintes análises nos 3 tipos de amostras: umidade, extrato etéreo (EE), matéria mineral ( $M M)$, fibra bruta (FB), proteína bruta (PB), matéria seca (MS), extrato não-nitrogenado (ENN), cálcio (Ca) e fósforo $(P)$ [6] e os valores observados foram comparados com os níveis de garantia declarados no rótulo pelo fabricante. Adotando-se uma tolerância de $10 \%$ na análise, de acordo com a legislação em vigor [7].

Os resultados foram analisados através do programa computacional Statistical Analysis System [8], sendo anteriormente verificada a normalidade dos resíduos pelo Teste de SHAPIRO-WILK (PROC UNIVARIATE) e a homogeneidade das variâncias comparadas pelo Teste QUI QUADRADO (Comando SPEC do PROC GLM). Os dados foram submetidos à análise de variância (PROC GLM), onde se avaliou o efeito do tipo de armazenagem sobre a composição bromatológica da ração (umidade, $P B, M M, E E, F B$ e ENN), sendo, em seguida, utilizado o teste de comparação de médias TUKEY. Para avaliar o efeito do tempo de armazenamento sobre a composição bromatológica da ração foi realizado análise de regressão (PROC REG). Foi adotado o nível de significância de 5\% para todas as análises realizadas.

\section{RESULTADOS}

Os resultados deste trabalho podem ser observados na tabela 2 e 3 e nas figuras 1 a 3 .

Quando comparado aos níveis de garantia do produto descrito na tabela 1. Pode-se observar que a quantidade de EE da amostra colhida após a abertura da embalagem foi inferior ao descrito nos níveis de garantia informados pelo fabricante. Estes resultados são contrários ao observado por Carciofi et al. (2006) [9] que avaliaram a relação entre a composição 
PEIXOTO JR, K.C., RODRIGUES, D.S. e FONTOLAN, V. Composição bromatológica de ração comercial para cães acondicionada de diferentes maneiras e por diferentes períodos. PUBVET, Londrina, V. 7, N. 16, Ed. 239, Art. 1579, Agosto, 2013.

bromatológica analisada em laboratório e os níveis de garantia de 49 marcas de rações adquiridas na região de Jaboticabal-SP e relataram que quando a concentração de EE esta fora dos valores informados nos níveis de garantia, esta apresentava-se acima dos níveis indicados pelo fabricante.

Tabela 2: Composição bromatológica da ração utilizada neste experimento analisada no dia da abertura da embalagem.

\begin{tabular}{ccccccc}
\hline UMIDADE & PB & EE & FB & MM & Ca & P \\
\hline $7,2 \%$ & $23,1 \%$ & $6,7 \%$ & $1 \%$ & $7,4 \%$ & $0,03 \%$ & $0,8 \%$ \\
\hline
\end{tabular}

A forma de armazenamento da ração não alterou a composição bromatológica da mesma, com exceção da umidade, que aumentou quando a ração foi armazenada aberta $(10,2 \% \times 7,5 \%$ e $7,8 \%)$ (tabela 3). Este aumento de umidade provavelmente ocorreu devido ao contato do pellet com a umidade do ar quando o saco de ração permaneceu aberto. O aumento linear da umidade ao longo das 7 semanas de armazenamento observado neste trabalho, contribui para justificar a suspeita de maior a absorção de umidade pelo produto quando armazenado aberto. No entanto, mesmo permanecendo por 7 semanas aberto, a umidade do produto permaneceu dentro dos padrões de qualidade indicados no rótulo pelo fabricante.

Tabela 3: Composição bromatológica de ração comercial para cão armazenada de diferentes maneiras.

\begin{tabular}{ccccccccc}
\hline TTO & UMIDAD & PB & EE & MM & ENN & FB (\%) & $\begin{array}{c}\text { Ca } \\
(\%)\end{array}$ & $\begin{array}{c}\text { P } \\
(\%)\end{array}$ \\
\hline Aberto & $10,2^{a}$ & $22,9^{a}$ & $5,7^{a}$ & $7,2^{a}$ & $54,1^{a}$ & $0,9^{a}$ & $0,29^{a}$ & $0,8^{a}$ \\
Fechado & $7,5^{\mathrm{b}}$ & $21,5^{\mathrm{a}}$ & $5,9^{\mathrm{a}}$ & $7,5^{\mathrm{a}}$ & $57,6^{\mathrm{a}}$ & $1,0^{\mathrm{a}}$ & $0,27^{\mathrm{a}}$ & $0,8^{\mathrm{a}}$ \\
Granel & $7,8^{\mathrm{b}}$ & $21,9^{\mathrm{a}}$ & $6,2^{\mathrm{a}}$ & $7,5^{\mathrm{a}}$ & $56,9^{\mathrm{a}}$ & $1,1^{\mathrm{a}}$ & $0,25^{\mathrm{a}}$ & $0,8^{\mathrm{a}}$ \\
\hline
\end{tabular}

*Médias com letras diferentes na mesma coluna são diferentes estatisticamente $(p<0,05)$. 
Ao observar alteração somente na umidade da amostra armazenada de forma aberta, este resultado é contrário ao descrito por Purina (1994) [10] que afirma que o excesso de umidade traz como conseqüência uma diluição do total de nutrientes das rações, reduzindo proporcionalmente seu valor nutritivo.

Quando se avaliou o efeito do tempo de armazenamento sobre a composição bromatológica da ração, foram observadas alterações significativas apenas nos valores de umidade, PB e EE. Houve regressão linear positiva para umidade (umidade $=7.4344+0,2895$ semana) (figura 1 ) e negativa para PB $(P B=24,69-0,711$ semana) (figura 2) e EE ( $E E=6,38-0,1465$ semana) (figura 3).

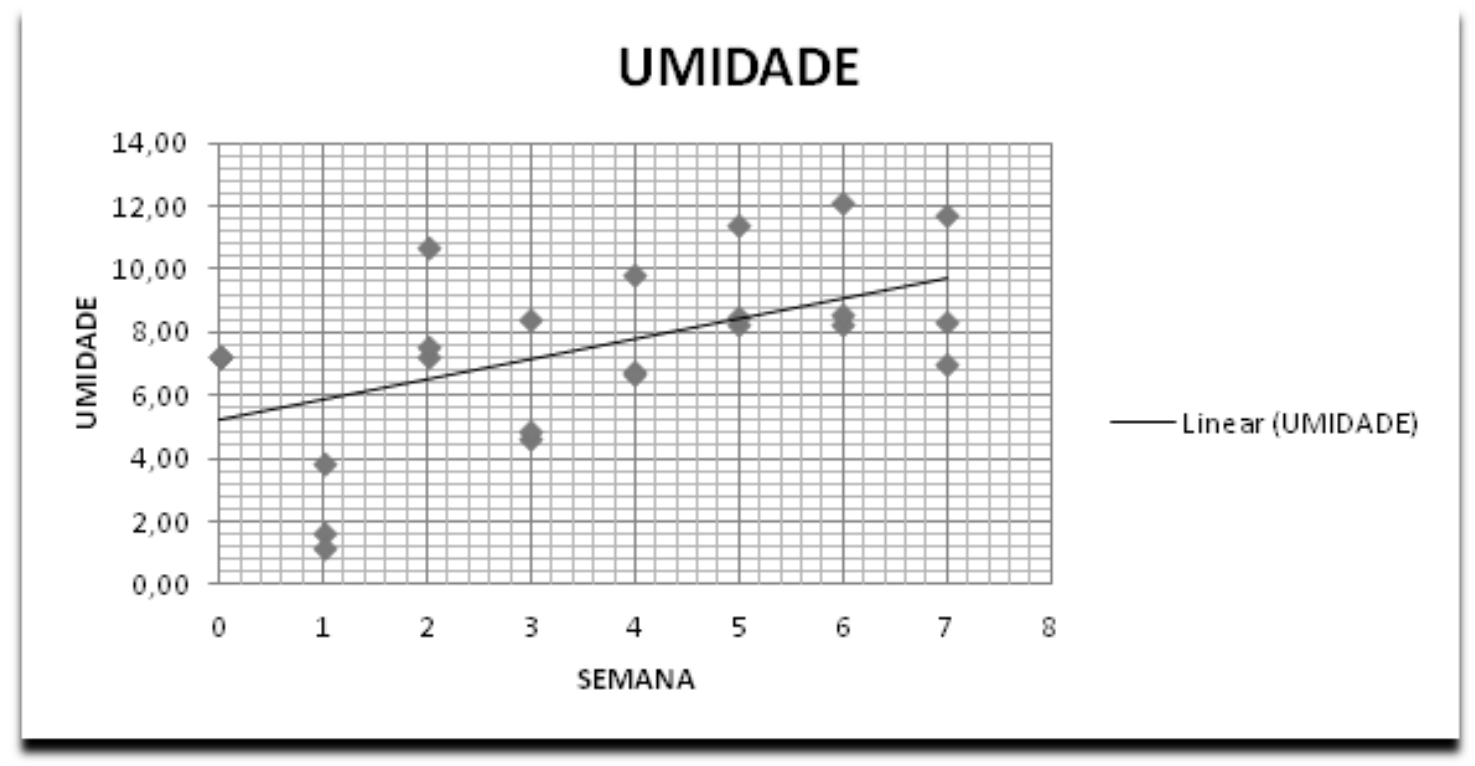

Figura 1: Umidade da ração em função do tempo de armazenamento.

A diminuição da quantidade de PB e EE da ração após aberta pode ter ocorrido devido a proteólise e oxidação respectivamente, ocasionados por bactérias e/ou fungos presentes no ambiente (figuras 2 e 3). Segundo Bellaver (2004) [12] a oxidação (rancidez oxidativa) ocorre pela ação de fatores como luz, umidade, temperatura elevada e presença de oxigênio. Com exceção da luz, todas as outras condições estavam presentes no local de armazenamento 
PEIXOTO JR, K.C., RODRIGUES, D.S. e FONTOLAN, V. Composição bromatológica de ração comercial para cães acondicionada de diferentes maneiras e por diferentes períodos. PUBVET, Londrina, V. 7, N. 16, Ed. 239, Art. 1579, Agosto, 2013.

das amostras de ração deste trabalho. Para Santos (2004) [13] se os alimentos forem devidamente processados, caberá a embalagem a função de protegê-los contra os fatores extrínsecos, tais como o oxigênio, a luz e o vapor d'água.

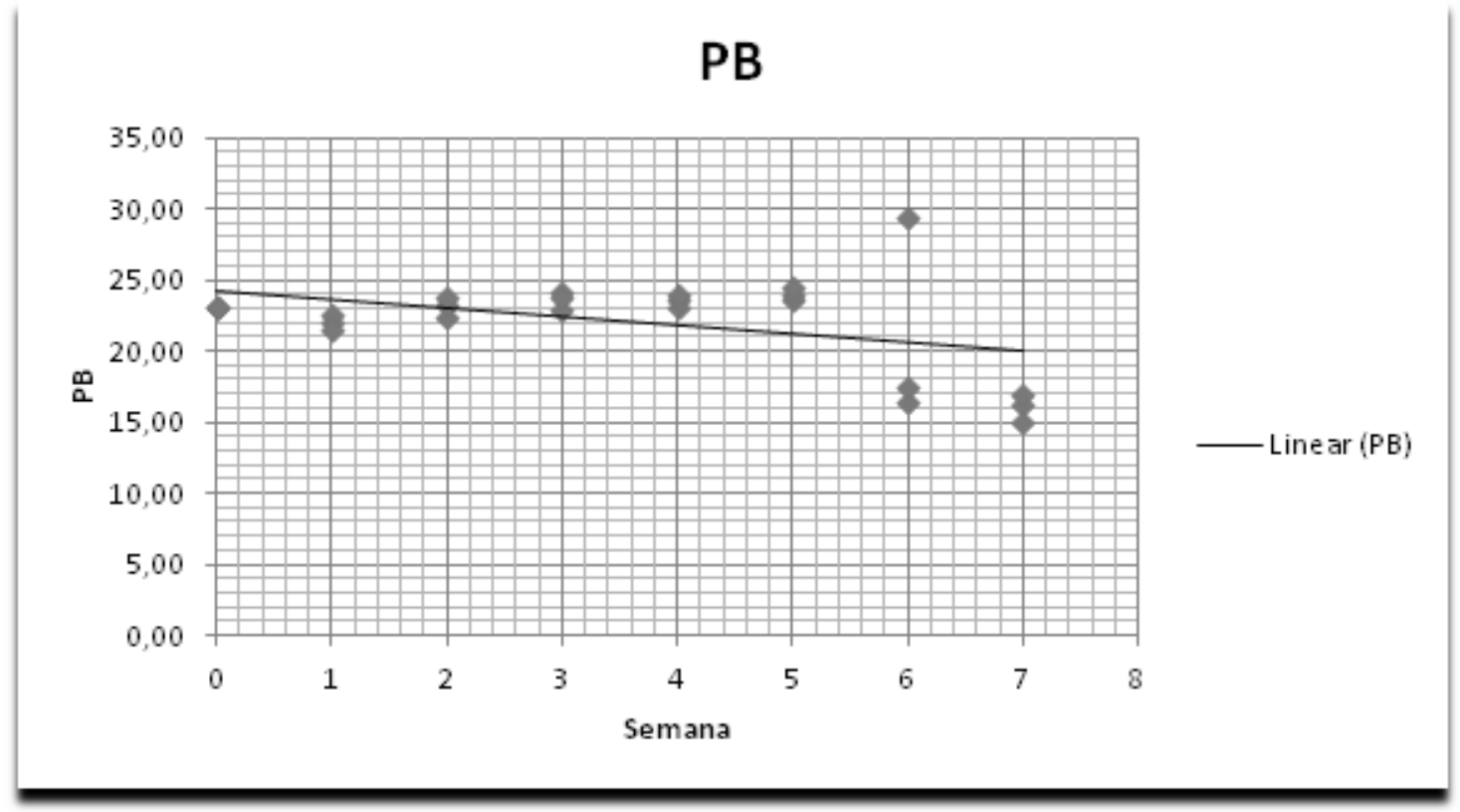

Figura 2: Proteína bruta da ração em função do tempo de armazenamento (PB $=24,69-0,711$ semana).

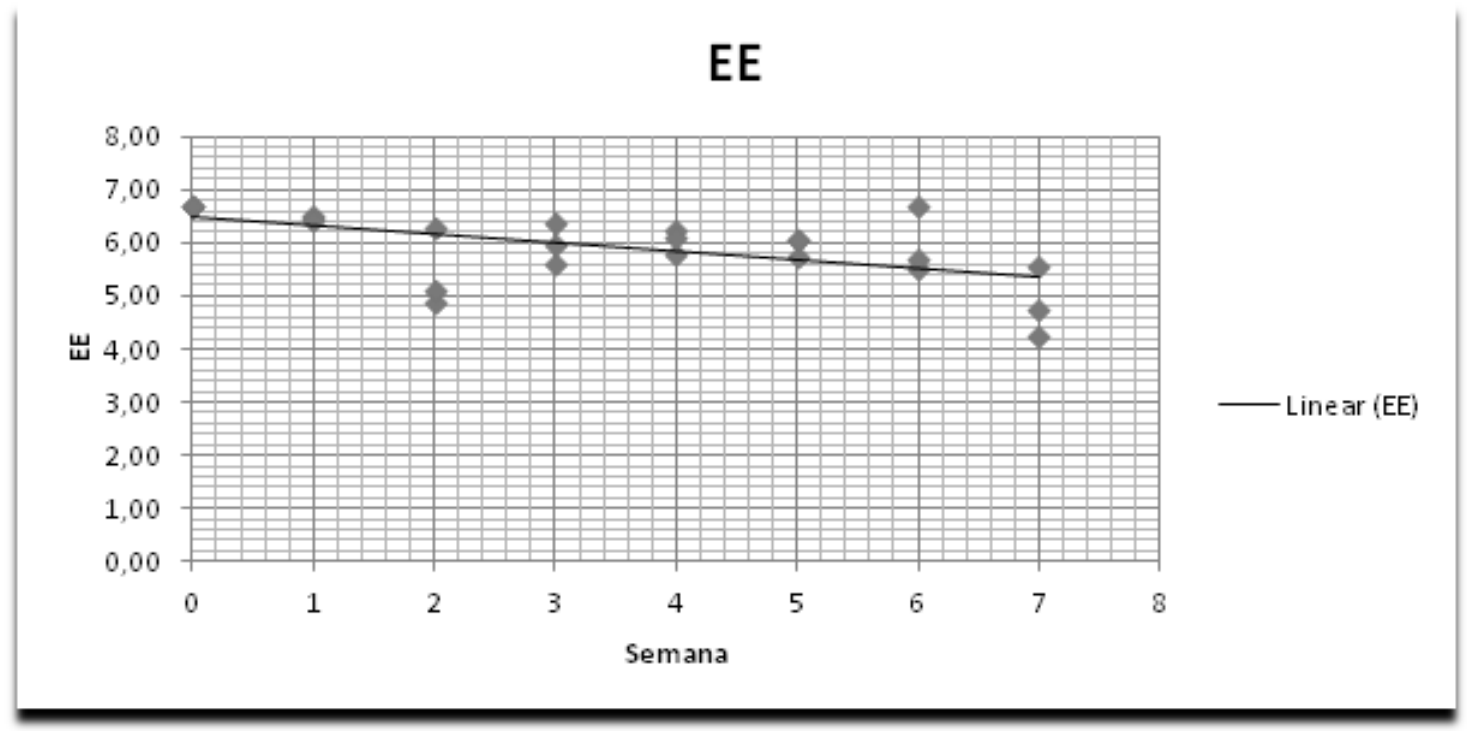

Figura 3: Extrato etéreo da ração em função do tempo de armazenamento $(\mathrm{EE}=6,38-0,1465$ semana $)$. 
PEIXOTO JR, K.C., RODRIGUES, D.S. e FONTOLAN, V. Composição bromatológica de ração comercial para cães acondicionada de diferentes maneiras e por diferentes períodos. PUBVET, Londrina, V. 7, N. 16, Ed. 239, Art. 1579, Agosto, 2013.

Embora neste trabalho a qualidade microbiológica da ração não tenha sido avaliada, esta suspeita pode ser comprovada pelas conclusões de Tonon et al., (1997) [14] que relataram que durante o período de armazenamento, o crescimento fúngico é uma grande causa de perda dos valores nutricionais do grão, de Andrade e Nascimento (2005) [4] que analisaram três amostras de ração comercializada em sacos abertos e venda a granel em relação aos sacos fechados na cidade de Pelotas-RS e observaram maior número de unidades formadoras de colônias de fungos nas amostras obtidas dos sacos abertos e a granel, por Mallmann et al. (2002) [15], que pesquisaram fungos em 17 tipos de ração para cães de 9 marcas diferentes, sendo 6 comercializadas a granel e 11 em embalagens individuais na cidade de Santa Maria - RS em 2002, e verificaram contaminação em $5(83,3 \%)$ amostras a granel e uma armazenada em embalagem individual ( $9 \%)$, concluindo que as rações a granel apresentam maiores contaminações por aflatoxinas, provavelmente devido à exposição à umidade e temperatura favorecendo o aparecimento deste contaminante e por Mallmann et al. (2003) [16] que avaliaram o grau de contaminação por aflatoxinas em rações destinadas a cães e relataram que das amostras analisadas, $58,8 \%$ apresentaram positividade, sendo que das amostras comercializadas a granel, $66 \%$ apresentaram contaminação, e entre as embaladas individualmente, $32,9 \%$ estavam contaminadas.

Para Bláha et al., (1990) [17] e Filtenborg et al., (1996) [18] o desenvolvimento fúngico pode resultar em diversas formas de deterioração: perda de sabor e aroma, perdas nutricionais de matérias-primas e alimentos completos; formação de toxinas, descoloração, apodrecimento e formação de propágulos alérgicos e patogênico.

Sítio Veg, (2000) [19] ao afirmar que o produto final pode perder sua esterilidade durante os processos de secagem, pulverização de gordura e empacotamento e Bernardi e Nascimento (2005) [20] para os quais rações armazenadas em sacos abertos e vendidas a granel contaminam-se através do contato com o ar e manuseio ajudam a explicar a regressão linear negativa na quantidade de proteína bruta e extrato etéreo observada neste trabalho. 
PEIXOTO JR, K.C., RODRIGUES, D.S. e FONTOLAN, V. Composição bromatológica de ração comercial para cães acondicionada de diferentes maneiras e por diferentes períodos. PUBVET, Londrina, V. 7, N. 16, Ed. 239, Art. 1579, Agosto, 2013.

Segundo Sítio Veg, (2000) [19] as rações comerciais secas estão freqüentemente contaminadas com bactérias, que podem ou não causar problemas e que o armazenamento impróprio, como o ocorrido neste trabalho, podem resultar na multiplicação dessas bactérias.

Os resultados deste trabalho podem ser utilizados para reforçar as conclusões de Bellaver (2001) [21] que afirmou que se os ingredientes adquiridos forem de alta qualidade, só existirão perdas, se o processamento, estocagem, transporte e uso forem inadequados.

\section{CONCLUSÕES}

Conclui-se que o armazenamento de rações abertas aumenta a umidade do produto e que a quantidade de PB e EE diminuem linearmente com o aumento do tempo de armazenamento.

\section{REFERÊNCIAS}

[1] MAPA - Ministério da Agricultura, Pecuária e Abastecimento. Instrução Normativa no. 9, de 09 de julho de 2003. Diário Oficial da República Federativa do Brasil, Seção 1, p. 7. 2003.

[2] SINDIRAÇÕES - Sindicato Nacional da Indústria de Alimentação Animal. Setor de Alimentação Animal - Boletim Informativo do Setor, 2011. Disponível em: http://www.agricultura.gov.br/arq editor/file/camaras setoriais/Aves e suinos/16RO/Boletim Sindira\%C3\%A7\%C3\%B5es.pdf. Acesso em: 11 jul. 2011.

[3] AC Nielsen do Brasil. Pesquisas de Mercado, 1997. Disponível em: www.bichoonline.com.br/artigos/gcao0001.htm. Acesso em: 18 jun. 2011.

[4] ANDRADE, R. M., NASCIMENTO, J. S. Presença de Fungos Filamentosos em Ração para Cães Comercializadas na Cidade de Pelotas - RS, Rio Grande do Sul, 2005.

Disponível em: www.ufpel.edu.br/cic/2005/arquivos/CB 01570.rtf. Acesso em: 09 abr. 2011.

[5] AOAC - ASSOCIATION OF OFFICIAL ANALYTICAL CHEMISTS . Official Methods of Analysis. 16.ed., Washington, D.C., p. 1117. 1995.

[6] SILVA, D. J. Análise de Alimentos: Métodos Químicos e Biológicos. $2^{\mathrm{a}}$ ed. Viçosa, Minas Gerais: Editora UFV, 1990.

[7] BRASIL. Ministério da Agricultura, Pecuária e Abastecimento. Decreto no 76.986, Diário Oficial da República Federativa do Brasil, Seção 1, p.499. Brasília, 07 de janeiro de 1976. 
[8] SAS INSTITUTE. Statistical Analysis Systems User's Guide: ETS. Versão 6, 1.ed., Cary: 1988.

[9] CARCIOFI A. C. et al. Composição nutricional e avaliação de rótulo de rações secas para cães adultos comercializadas em Jaboticabal-SP. Arquivo Brasileiro de Medicina Veterinária e Zootecnia. vol. 58, n. 03. Jun. 2006.

[10] PURINA. Boletim de Controle de Qualidade. São Paulo - SP, 1994.

[12] BELLAVER, C. Ingredientes de Origem Animal Destinados à Fabricação de Rações. In: Simpósio sobre Ingredientes na Alimentação Animal, Campinas: SP, abr, 2004.

[13] SANTOS, K. A. Estabilidade da Erva-mate (Ilex paraguariensis St. Hill.) em Embalagens Plásticas. Teses. Curso de Engenharia Química, Curitiba p. 107, 2004.

[14] TONON, S. A.; MARUCCI, R. S.; JERKE, G.; GARCÍA, A. Mycoflora of Paddy and Milled Rice Produced in the Region of Northeastern Argentina and Southern Paraguay. International Journal of Food Microbiology, Amsterdam, v. 37, n. 2, p. 231-235, jul. 1997.

[15] MALLMANN, C. A.; MÜRMANN, L; KOWALSKI, C. H.; SILVEIRA, V. G. Níveis de Contaminação por Aflatoxinas em Rações Animais. In: XXIV Congresso Brasileiro de Medicina Veterinária, Anais... Gramado - RS. 2002.

[16] MALLMANN, C. A. et al. Níveis de Aflatoxinas em Rações Caninas. In: XIII Congresso Brasileiro de Toxicologia, Londrina. Revista Brasileira de Toxicologia, v.16, p.40, 2003.

[17] BLÁHA, J.; JÍCÍNSKÁ, E.; VESELÝ, D.; JELÍNEK, R. The Effect os Moulds on the Nutritional Value of Wheat. Animal Feed Science and Technology, v. 28n. 3-4p. 315-324, 1990.

[18] FILTENBORG, O.; FRISVAD, J.C.; THRANE, U. Moulds in Food Spoilage. International Journal of Food Microbiology, v.33, p. 85-102, 1996.

[19] SÍTIO VEG. O Processo de Fabricação de Ração, 2000. Disponível em: http://www.vegetarianismo.com.br/sitio/index.php?option=com content\&task=view\&id $=383 \&$ Itemid=34. Acesso em: 12 fev. 2011.

[20] BERnARDi, E.; NASCIMENTO, J. S. do. Fungos Anemófilos na Praia do Laranjal, Pelotas, Rio Grande do Sul, Brasil. Arq. Inst. Biol., São Paulo, v.72, n.1, p.93-7, 2005.

[21] BellaVer, C. Processamento e Cuidados com Produtos de Origem Animal: Higiene e Profilaxia. In: Simpósio sobre Manejo e Nutrição de Aves e Suínos e Tecnologia da Produção de Rações, Campinas: SP, nov, 2001. 